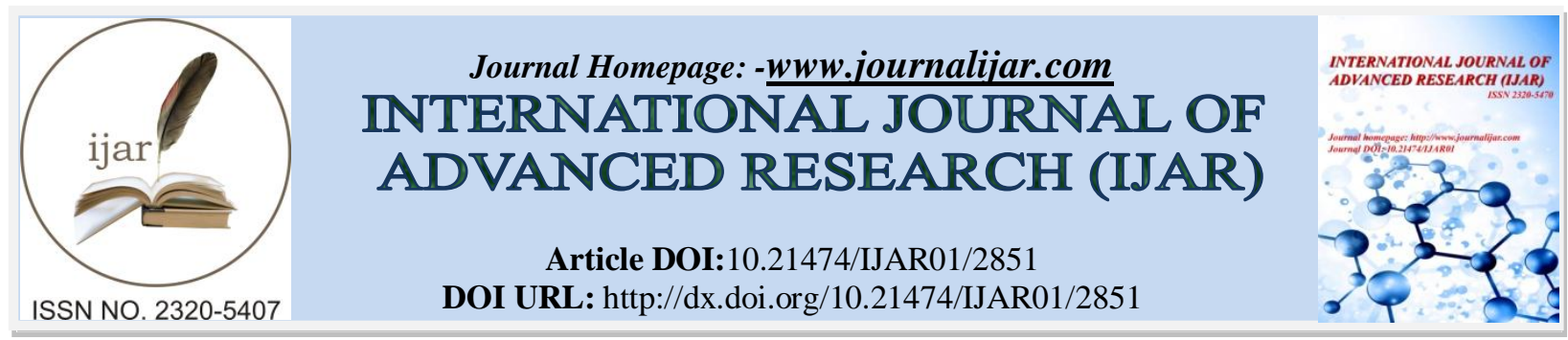

\title{
RESEARCH ARTICLE \\ GENETIC DIVERSITY STUDIES IN SIX BIVOLTINE RACES OF BOMBYX MORI L., BASED ON PHENOTYPIC CHARACTERS.
}

*Anita Kumari and N.K.Tripathi.

Department of Zoology, University of Jammu, Jammu and Kashmir-180006, India.

\section{Manuscript Info \\ Manuscript History \\ Received: $x x x x x x x x x x x x x x x$ \\ Final Accepted: $x x x x x x x x x x x x$

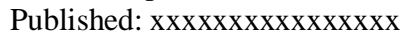

\section{Key words:-}

Sericulture, silkworm, bivoltine, cocoon, Jam races, Bombyx mori, UPGMA, Pam races.

\begin{abstract}
Comparative studies of phenotypic characters in some developmental stages of mulberry silkworm, Bombyx mori. L was carried out in order to access their genetic diversity. Three Jam and three Pam races evolved in J\&K were selected for the study. The egg, larvae and cocoon stage were studied for the various phenotypic and economic parameters; these qualitative and quantitative characters were put into various statistical analysis like correlation studies of length and weight changes during $\mathrm{V}$ instar and clustering on the basis of UPGMA, Ward's method and Single linkage analysis. Results indicated highly significant differences for all the studied characters; high positive correlation between larval length and weight change during the $\mathrm{V}$ instar larval stage, Also, the races were divided into few clusters/groups on the basis of weight gain characteristics. The present study will help in selection of parents for various breeding programmes and evolving new locally acclimatized, high yielding superior quality silk producing races.
\end{abstract}

Copy Right, IJAR, 2016,. All rights reserved.

\section{Introduction:-}

The silkworm B. mori was domesticated over 5000 years ago (Nagaraju and Goldsmith, 2002) and is well known for its industrial importance in sericulture (Goldsmith et al., 2005). It has a number of varieties viz; univoltine, bivoltine, and polyvoltine. B.mori has become a model organism for studying other lepidopteron insects that cause serious agricultural damage and is also an important model for scientific discovery in the areas of microbiology, physiology and genetics.

silkworm breeds play a vital role in the success of sericulture industry. Thus the breed development and improvement is a continuous process which aims at providing suitable genotypes with desired traits (Datta, 1984; Rao et al., 2006). Enrichment of silkworm breeds / hybrids have always been one of the important factors contributing to increase the productivity in sericulture sector. Continuous development, evaluation, renewal and change of existing breeds/hybrids with new superior varieties and their commercialization is the prime factor to increase silk quality and quantity (Chandrashekharaiah and Ramesh Babu, 2003).

The state of Jammu and Kashmir is known for producing bivoltine silk of international quality. Being one of the traditional agro-based industries of the state producing high quality bivoltine silk comparable to international quality helps in improving the economic conditions of landless farmers and weaker sections of the society and providing employment opportunities during pre- and post cocoon activities. Realizing the importance of sericulture, the 
genetic diversity of the silkworm should be maintained and analyzed for various traits so that it may help in evolving new locally acclimatized, high yielding superior quality silk producing breeds.

In the present study, six bivoltine races of B.mori were reared in sub-tropical conditions of Jammu, assuring the same micro-climate conditions, being fed with same variety of mulberry leaves. The egg, larval, and cocoon characters were analyzed for the differences and similarities. Agglomerative hierarchial clustering was done for the weight gain during the $\mathrm{V}$ instar development and dendrograms were prepared based on different indices that may help in selective breeding.

\section{Material And Methods:-}

The study was conducted in Regional Sericulture Research Station, MiranSahib (RSRS, Miran Sahib) and Department of Zoology, University of Jammu simultaneously during Feb-Apr 2013. For the present study, two disease free layings (DFL's) each of six races ( Jam 103, Jam 110, Jam 118, evolved in Jammu were obtained from RSRS, MiranSahib, Jammu and Pam 101, Pam 102, Pam 103 evolved in pampore were transported from CSRT\&TI, pampore. Eggs were incubated for 9-12 days in a neat and clean, disinfected room at 80-85\% Humidity and 24$25^{\circ} \mathrm{C}$ Temperature with $18 \mathrm{hrs}$ light till pin head stage, at this stage black -boxing was done to ensure maximum hatching on exposure to bright light. The hatched larvae were reared separately under uniform laboratory conditions as described by Yokoyama (1963) and Krishnaswami (1978).

During the entire period of research, same micro-climate and feeding conditions were ensured as per the larval stage (Table 1). The whole evolutive period was studied for Egg, Larval and Cocoon characters as follows:

At egg stage: egg shape, egg colour, hatching percentage and average fecundity per female moth were studied. At larval stage: larval colour, markings, mean length and mean weight of 10 larvae on each day of $\mathrm{V}$ instar were studied and analyzed. Correlation of larval length and weight was done and changes in length and weight of larvae of different races were compared. The statistical analysis was done with the help of software PRIMER. Length of larvae was measured with the help of vernier calipers and weight of larvae was measured with electronic balance.

Measurements performed for the determination of length and weight of 10 larvae, were done at each day of $\mathrm{V}$ instar larvae at 11:00 a.m. for five days before cocooning. The results obtained show high homogeneity in different races. The larval weight from day 1 to day 5 of $\mathrm{V}$ instar larvae was subjected to cluster analysis and similarity matrix was obtained. The races were clustered into different groups on the basis of Euclidean distances according to grouping from UPGMA method, ward's method and single linkage using PAST 3 and relationships were represented as Dendrograms. At cocoon stage: cocoon shape, cocoon colour and cocoon grain was noted.

\section{Results And Discussion:-}

Egg Stage: Analyzing the biological parameters of eggs, colour of eggs was granite grey for all Jam races and Pam 101, while eggs of Pam 102 were nut brown and of Pam 103 were steel grey. Shape of eggs of different races being same, the highest average fecundity per moth was 515 in Pam 101 and lowest was 302 in Pam 102. The lowest hatching percent $(89.31 \%)$ was obtained in Pam102 race and the highest (94.34\%) was obtained in Jam 110 race, with a mean of $93.23 \%$ in all studied races. (Table 2).

Larval stage: The biological characters of larval stages were recorded as given (Table 3). Under ideal conditions it has been reported that the total larval duration is 25-30 days (Raina, 2000). The total larval duration in the studied races was 23-25 days with maximum in Jam 103 (24.38 days) and minimum in Pam 102 (23.11days). The V age larval duration was also maximum in Jam 103 and Jam 118 (6.05 days) and minimum in Pam 102 (5. 54days). The V age 5 day larval colour was steel grey in Jam 110, Jam 118, Pam 103 and marble grey in Jam 103, Pam 101, Pam 102. All the larvae were plain with semi-plain in Pam 101 and marked in Pam 103. (Fig 1-fig 6). The length and weight of 10 larvae, is given in Table 4 and Table 5. The length of each race was correlated with the weight on each day. The results obtained show high homogeneity in different races with highest correlation coefficient in Jam 118 (0.9966) and lowest in Pam 102 (0.9799)(Table 6). The larval weight from day 1 to day 5 of V instar larvae was subjected to cluster analysis and similarity matrix was obtained (Table 7). The races were clustered into different groups on the basis of Euclidean distances according to grouping from UPGMA method, ward's method and single linkage using PAST 3 and relationships were represented as Dendrograms.(fig. 7, fig 8. and fig.9.) 
Cocoon stage: Of these few phenotypic characters studied, all the races have oval shaped cocoons except Pam 101having elongated constricted shape and Pam 102 with constricted shape, cocoon colour being white as of bivoltine races and cocoon grain medium in all except Jam 103 and Pam 103 with fine grain. (Table 8). (Fig 10-fig 15)

Varietal differences for studied traits in B.mori has been reported by Ahsan et al., 2000, Li et al., 2001; Furdui et al., 2010. Similar studies on varietal diversity have also been sustained by the findings of Reza et al.,1993, Mistri and Jayaswal, 1992; Ahsan et al.,1999; Umashankara and Subramanya, 2002; Nezhad et al., 2009; Nguku et al., 2007; Nguku et al., 2009; Zannata et al., 2009; Pal and Moorthy 2011). The Cluster analysis (UPGMA) divided the 6 strains into 2 groups as shown in (fig.1, fig.2 and fig.3). All races were grouped together and 2 were far from other silkworm strains, indicating it might be suitable for future crossings, maintenance of germplasm so as to maximize heterosis and to avoid inbreeding depression. As studied by Peters et al 1989 UPGMA yields more accurate results for classification purposes than other hierarchial methods.

Table 1:- Temperature and Humidity conditions at various instars of Silkworm life cycle.

\begin{tabular}{|r|r|r|}
\hline Instar & Temperature $\left({ }^{\circ} \mathbf{C}\right)$ & Humidity (\%) \\
\hline I & $26-28$ & $85-90$ \\
\hline II & $26-28$ & $85-90$ \\
\hline III & $24-26$ & 80 \\
\hline IV & $24-25$ & $70-75$ \\
\hline V & $23-24$ & $65-70$ \\
\hline
\end{tabular}

Table 2:-Biological characters of eggs of different races.

\begin{tabular}{|l|l|l|l|l|}
\hline Race & $\begin{array}{l}\text { Colour of } \\
\text { hibernating eggs }\end{array}$ & Shape & $\begin{array}{l}\text { Average } \\
\text { fecundity } \\
\text { per moth }\end{array}$ & $\begin{array}{l}\text { Hatching } \\
\text { percentage(\%) }\end{array}$ \\
\hline Jam 103 & Granite grey & Ellipsoid & 406 & 94.21 \\
\hline Jam 110 & Granite grey & Ellipsoid & 414 & 94.34 \\
\hline Jam 118 & Granite grey & Ellipsoid & 417 & 94.19 \\
\hline Pam 101 & Granite grey & Ellipsoid & 515 & 93.99 \\
\hline Pam 102 & Nut brown & Ellipsoid & 302 & 89.31 \\
\hline Pam 103 & Steel grey & Ellipsoid & 332 & 93.39 \\
\hline
\end{tabular}

Table 3:- Biological characters of larvae of different races.

\begin{tabular}{|l|l|l|l|l|}
\hline Race & $\begin{array}{l}\text { Total larval } \\
\text { duration(days) }\end{array}$ & $\begin{array}{l}\text { V age } \\
\text { larval duration(days) }\end{array}$ & $\begin{array}{l}\text { Larval colour } \\
\text { V age 5 day }\end{array}$ & $\begin{array}{l}\text { Larval marking } \\
\text { (V age) }\end{array}$ \\
\hline Jam 103 & 24.38 & 6.05 & Marble grey & Plain \\
\hline Jam 110 & 24.08 & 6.00 & Steel grey & Plain \\
\hline Jam 118 & 23.52 & 6.05 & Steel grey & Plain \\
\hline Pam 101 & 24.08 & 5.83 & Marble grey & Semi-Plain \\
\hline Pam 102 & 23.11 & 5.54 & Marble grey & Plain \\
\hline Pam 103 & 23.30 & 6.00 & Steel grey & Marked \\
\hline
\end{tabular}

Table 4:- Length of different races of $V$ instar larvae from Day 1 to Day 5 in $\mathrm{cm}$ (Mean \pm S.D).

\begin{tabular}{|l|l|l|l|l|l|l|}
\hline S.No. & Race & Day 1 & Day 2 & Day 3 & Day 4 & Day 5 \\
\hline .1 & Jam 103 & $4.36 \pm 0.271$ & $4.935 \pm 0.266$ & $5.465 \pm 0.316$ & $5.99 \pm 0.230$ & $6.315 \pm 0.163$ \\
\hline .2 & Jam 110 & $4.525 \pm 0.241$ & $4.885 \pm 0.310$ & $5.465 \pm 0.286$ & $5.965 \pm 0.240$ & $6.245 \pm 0.195$ \\
\hline .3 & Jam 118 & $4.55 \pm 0.283$ & $4.89 \pm 0.231$ & $5.384 \pm 0.300$ & $6.01 \pm 0.235$ & $6.3 \pm 0.200$ \\
\hline .4 & Pam 101 & $4.665 \pm 0.184$ & $5.0 \pm 0.154$ & $5.47 \pm 0.277$ & $6.275 \pm 0.145$ & $6.49 \pm 0.182$ \\
\hline .5 & Pam 102 & $4.61 \pm 0.290$ & $4.95 \pm 0.278$ & $5.545 \pm 0.244$ & $6.315 \pm 0.251$ & $6.575 \pm 0.196$ \\
\hline .6 & Pam 103 & $4.35 \pm 0.176$ & $4.835 \pm 0.193$ & $5.24 \pm 0.234$ & $5.84 \pm 0.260$ & $6.195 \pm 0.187$ \\
\hline
\end{tabular}


Table 5:- Weight of different races of $V$ instar larvae from Day 1 to Day 5 in $g$ (Mean \pm S.D).

\begin{tabular}{|c|l|l|l|l|l|l|}
\hline S.No. & Race & Day 1 & Day 2 & Day 3 & Day 4 & Day 5 \\
\hline .1 & Jam 103 & $1.136 \pm 0.122$ & $1.66 \pm 0.211$ & $2.269 \pm 1.61$ & $3.425 \pm 0.616$ & $3.787 \pm 0.678$ \\
\hline .2 & Jam 110 & $1.057 \pm 0.169$ & $1.529 \pm 0.343$ & $2.225 \pm 0.347$ & $3.602 \pm 0.343$ & $3.952 \pm 0.347$ \\
\hline .3 & Jam 118 & $0.894 \pm 0.102$ & $1.365 \pm 0.137$ & $2.01 \pm 0.224$ & $3.262 \pm 0.372$ & $3.615 \pm 0.375$ \\
\hline .4 & Pam 101 & $1.693 \pm 0.082$ & $2.018 \pm 0.097$ & $2.875 \pm 0.274$ & $3.663 \pm 0.196$ & $3.825 \pm 0.216$ \\
\hline .5 & Pam 102 & $1.449 \pm 0.201$ & $2.077 \pm 0.253$ & $3.095 \pm 0.177$ & $3.637 \pm 0.297$ & $3.861 \pm 0.247$ \\
\hline .6 & Pam 103 & $1.309 \pm 0.161$ & $1.908 \pm 0.223$ & $2.585 \pm 0.436$ & $3.183 \pm 0.271$ & $3.296 \pm 0.254$ \\
\hline
\end{tabular}

Table 6:- Correlation studies of increase in length and weight gain in day 1 to day 5 of V instar larvae of different races.

\begin{tabular}{|l|l|l|l|l|l|l|}
\hline & Jam 103 & Jam 110 & Jam 118 & Pam 101 & Pam 102 & Pam103 \\
\hline $\begin{array}{l}\text { Correlation } \\
\text { coefficient(r) }\end{array}$ & 0.9864 & 0.9873 & 0.9966 & 0.9924 & 0.9799 & 0.9847 \\
\hline
\end{tabular}

Table 7:-Similarity/distance index based on Euclidean distances.

\begin{tabular}{|l|l|l|l|l|l|l|}
\hline & Jam 103 & Jam 110 & Jam 118 & Pam 101 & Pam 102 & Pam 103 \\
\hline Jam 103 & 0 & 0.289641 & 0.518481 & 0.929375 & 1.002274 & 0.700667 \\
\hline Jam 110 & 0.289641 & 0 & 0.573462 & 1.042097 & 1.104705 & 0.970898 \\
\hline Jam 118 & 0.518481 & 0.573462 & 0 & 1.420541 & 1.480991 & 0.951683 \\
\hline Pam 101 & 0.929375 & 1.042097 & 1.420541 & 0 & 0.336733 & 0.868272 \\
\hline Pam 102 & 1.002274 & 1.104705 & 1.480991 & 0.336733 & 0 & 0.913018 \\
\hline Pam 103 & 0.700667 & 0.970898 & 0.951683 & 0.868272 & 0.913018 & 0 \\
\hline
\end{tabular}

Table 8:- Biological characters of cocoon of different races.

\begin{tabular}{|l|l|l|l|}
\hline Race & Shape & Colour & Grain \\
\hline Jam 103 & Oval & White & Fine \\
\hline Jam 110 & Oval & White & Medium \\
\hline Jam 118 & Oval & White & Medium \\
\hline Pam 101 & Elongated Constricted & White & Medium \\
\hline Pam 102 & Constricted & White & Medium \\
\hline Pam 103 & Oval & White & Fine \\
\hline
\end{tabular}

Fig 1-fig 6:- Showing Vth instar larval markings in 6 B.mori races

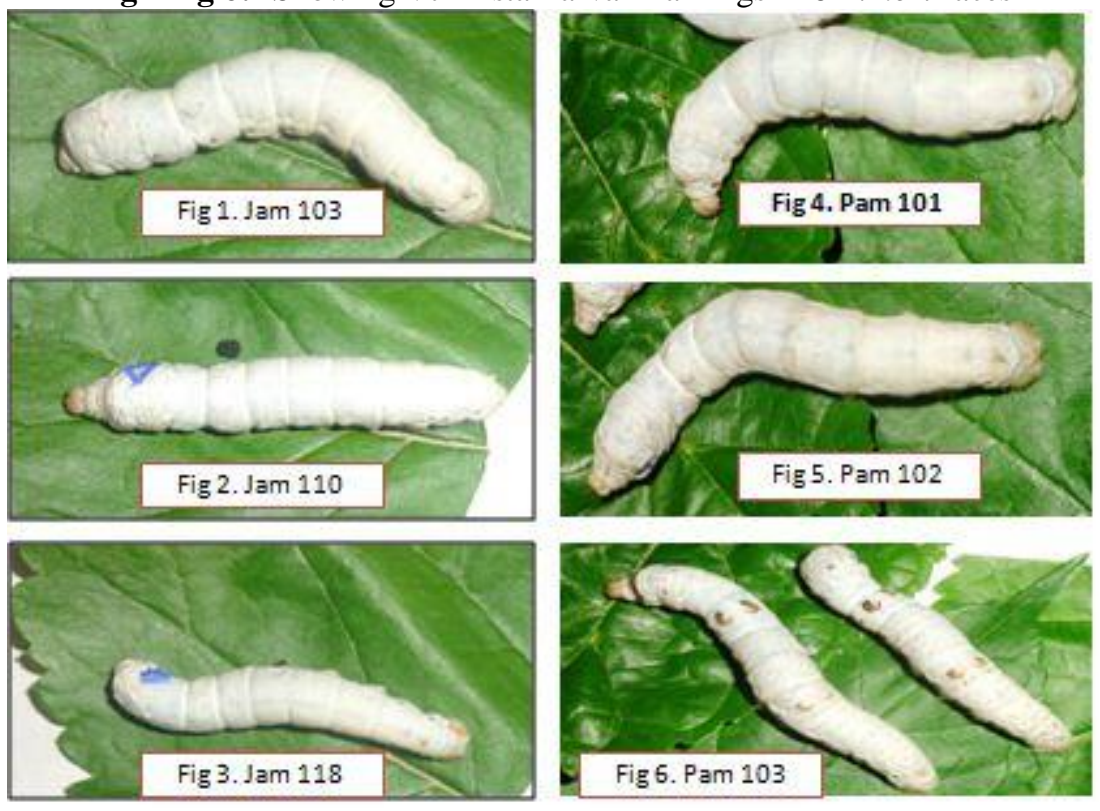


Fig. 7:- Dendrogram based on similarity matrix using UPGMA.

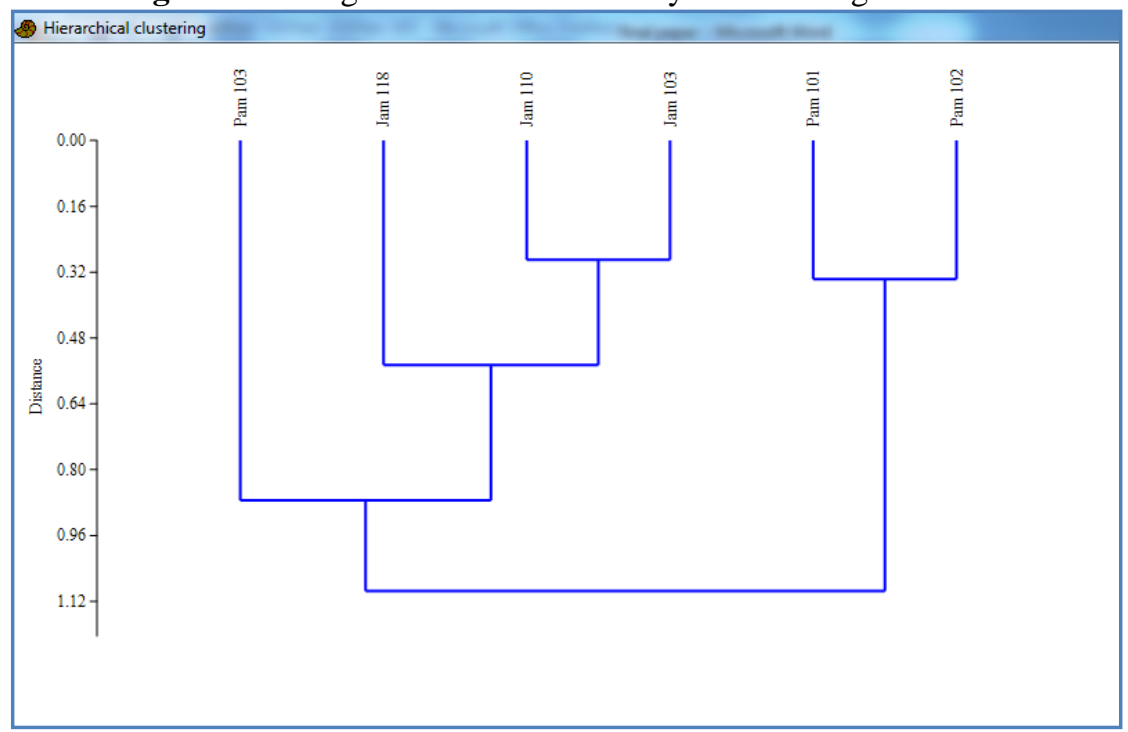

Fig 8:- Dendrogram based on similarity index using single linkage analysis.

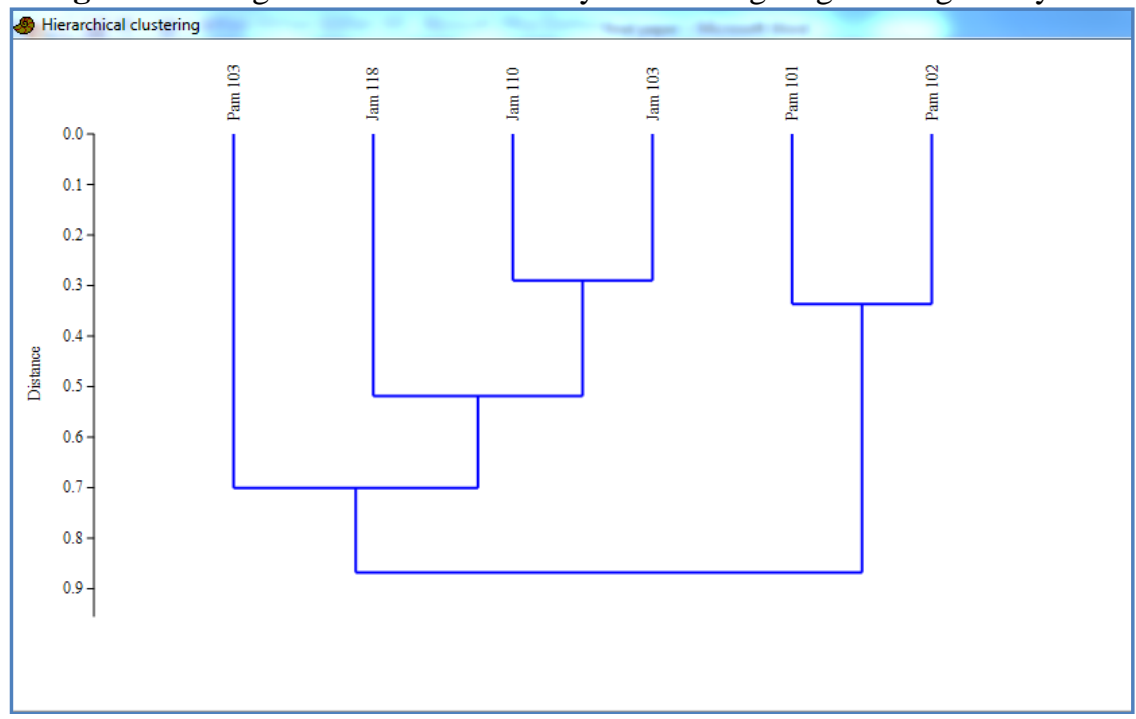

Fig 9:- Dendrogram based on similarity index using Ward's method.

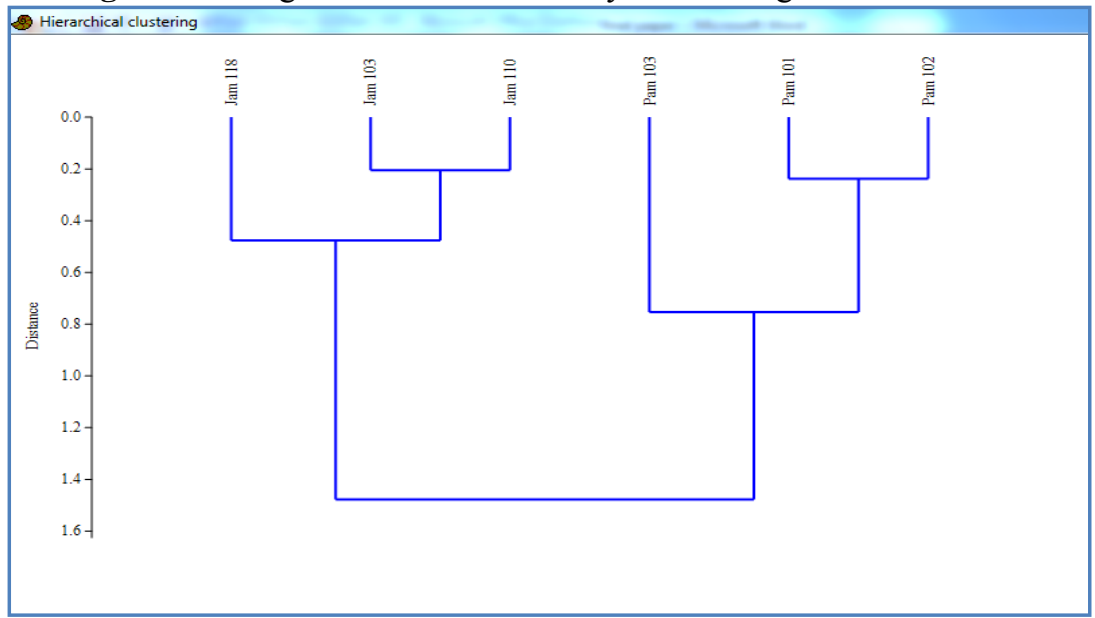


Fig 10- fig 15:- showing cocoon shape in 6 B.mori races studied.

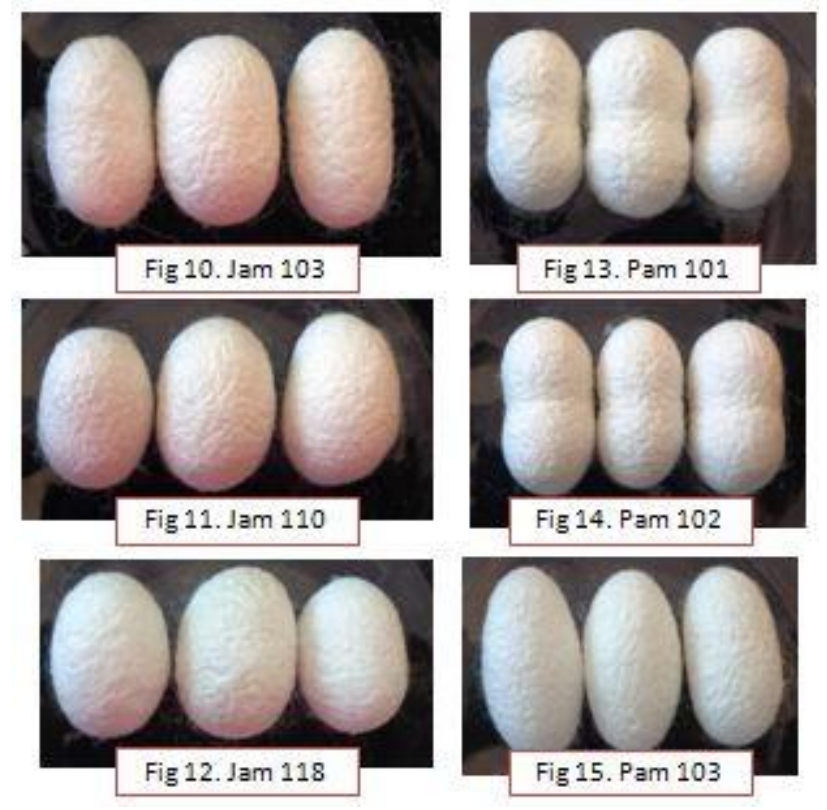

\section{Conclusion:-}

The obtained data showed that there are highly significant differences among the races for all the studied characters. There is a high positive correlation between larval length and weight during $\mathrm{V}$ instar. The differences in obtained results are due to the variability and genotype characters for each individual of every race.

\section{Acknowledgements:-}

Author is highly thankful to Prof. Roopma Gandotra, HOD Zoology, University of Jammu for providing necessary Lab facilities. Thanks are also due to Dr. S.K.Raina, Deputy Director, RSRS, Miransahib for providing seeds of Jam races and necessary rearing conditions and CSR\&TI, Pampore, for providing seeds of Pam races for present study. Author is indebted to CSIR for providing financial assistance.

\section{References:-}

1. Ahsan, M.K., Rahman, S.M. \& Ali, I.A. (1999). Inheritance of some quantitative traits in fifteen indigenous varieties of silkworm, Bombyx mori L. Univ.J. Zool. Rajshahi Univ.18: 79-83.

2. Ahsan, M.K., Rahman, S.M. \& Ali, I.A. (2000). Variability of some quantitative traits in the hybrids of silkworm, Bombyx mori L. Univ. J. Zool. Rajshahi Univ. 19: 20-24.

3. Datta, R.K. (1992). Guidelines for Bivoltine Rearing.Central Silk Board, Bangalore, India, p.18.

4. Furdui, E.M., Marghitas, L.A., Dezmirean, D., Mihai, C.M., Bobis, O and Pasca, I. (2010). Comparative study of biological characters of larvae, crude and dried cocoon in 7 races of Silkworm Bombyx mori L., raised in Transylvania area. Scientific Papers: Animal Science and Biotechnologies, 43(1): 490-493.

5. Goldsmith, M. R. (1995). Genetics of the silkworm: revisiting an ancient model system. In Molecular Model Systems in the Lepidoptera, ed. MR Goldsmith, AS Wilkins, pp. 21-76. New York: Cambridge Univ. Press

6. Goldsmith, M. R., Shimada, T and Abe, H. (2005). The genetics and genomics of the silkworm, Bombyx mori. Annu Rev Entomol, 50: 71-100.

7. Krishnaswami S. (1978). New technology of silkworm rearing in Bulletin No. 2, Central Sericultural research and Training Institute, Mysore, Central Silk Board, Govt. of India, 1-23.

8. Li, M., Qin, Y., Hou, C., Lin, C and Chen K. (2001). Studies on some special characters in the silkworm (Bombyx mori L.) germplasms in China. Sericologia41: 527-35

9. Mistri, P. K. \& Jayaswal, K. P. (1992). Studies on phenotypic correlations between some economic traits of silkworm, Bombyx mori L. Bull. Seric. Res. 3: 26-29

10. Nagaraju, J., Goldsmith, M. R. (2002). Silkworm genomics - progress and prospects. Curr Sci 83: 415-425. 
11. Nezhad, M.S., Mirhosseini, S.Z., Gharahveysi, S., Mavvajpour, M and Seidavi, A.R. (2009). Analysis of Genetic Divergence for classification of morphological and larval gain characteristics of peanut cocoon silkworm (Bombyx mori L.) Germplasm. American-Eurasian J. Agric. \& Environ. Sci., 6(5): 600-608.

12. Nguku, E.K., Adolkar, V.V., Raina, S.K., Mburugu, K.G., Mugenda, O.M and Kimbu, D.M.(2009). Performance of six Bivoltine Bombyx mori. (Lepidoptera: Bombyxidae) silkworm strains in Kenya.The Open Entomology Journal, 3, 1-6.

13. Nguku, E.K.,Muli, E.M and Raina S.K.(2007). Larvae, cocoon and post-cocoon Characteristics of Bombyx mori L.(Lepidoptera:bombyxidae) fed on mulberry leaves fortified with Kenyan royal jelly. J. Appl. Sci. Environ. Manage.11(4) 85-89

14. Pal, N. B and Moorthy, S. M. (2011). Assessment of variability in larval and cocoon traits in some genotypes of bivoltine silkworm,Bombyx mori L. International Journal of Research in Biological Sciences, 1(4): 59-65.

15. Peters, J.P and Martinelli, J.A. (1989). Hierarchial cluster analysis as a tool to manage variation in germplasm collection. Theor. Appl. Genet., 78:42-48.

16. Rao, C.G., Seshagi, S.V., Ramesh, C., Ibrahim, B.K and Nagaraju, H., Chandrashekharaiah. (2006). Evaluation of genetic potential of the polyvoltine silkworm (Bombyx mori L.) germplasm and identification of parents for breeding programme. J. Zhejiang Univ Sci B 7: 215-220.

17. Reza, A. M. S., Rahman, M. S. \& Rahman, S. M. (1993). Studies on the variation of some larval traits in different breeds of silkworm, Bombyx mori L. Univ. J. Zool. Rajshahi Univ. 12: 21-24.

18. Umashankara, M. L. and Subramanya, G. (2002). Correlation between larval weight and cocoon characters in five breeds of silkworm, Bombyx mori L. Geobios, 29:154-157.

19. Yokoyama T. (1963). Sericulture. Ann. Rev. Entomol. 8:87-306.

20. Zanatta, D.B., Bravo, J.P., Barbosa, J.F., Munhoz, R.E.F and Fernandez, M.A. (2009). Evaluation of economically important traits from sixteen parental strains of the silkworm Bombyx mori L.(Lepidoptera: Bombyxidae). Neotropical Entomology 38(3): 327-331. 